\title{
SILENCIAMENTO DOS ENFERMEIROS SOBRE OS MOTIVOS DA NÃO RECOMENDAÇÃO DA AMAMENTAÇÃO CRUZADA
}

Cristiane Santos Gomes ${ }^{1}$

Benedita Maria Rêgo Deusdará Rodrigues ${ }^{2}$

Patricia Lima Pereira Peres ${ }^{2}$

Lilian Koifman ${ }^{3}$ https://orcid.org/0000-0002-8538-7122

https://orcid.org/0000-0002-1558-4219

https://orcid.org/0000-0001-7086-8970

https://orcid.org/0000-0003-1038-3490

Objetivo: identificar qual a conduta assistencial do enfermeiro frente à amamentação cruzada. Método: estudo qualitativo, realizado com seis enfermeiras atuantes da Estratégia de Saúde da Família por meio de um grupo focal em de Duque de Caxias. Resultados: aponta a carência do aconselhamento na conduta assistencial frente à amamentação cruzada e o silenciamento sobre os motivos da não recomendação da mesma. Conclusão: Recomenda-se mudança nos discursos dos enfermeiros para a busca dos motivos que desencadearam a prática da amamentação cruzada para assim poderem intervir, visto que na maioria das vezes é praticada pela não efetividade de seus direitos.

Descritores: Aleitamento materno; Aconselhamento; Enfermagem; Bioética.

\section{SILENCING OF NURSES ON THE REASONS FOR NOT RECOMMENDING CROSS-BREASTFEEDING}

Objective: identify the nurse's care practice towards cross-breastfeeding. Method: a qualitative study carried out with six nurses working in the Family Health Strategy through a focus group in Duque de Caxias. Results: points out the lack of counseling in the care practice regarding cross-breastfeeding and the silencing of the reasons for not recommending it. Conclusion: it is recommended to change the nurses's discourses to search for the reasons that triggered the practice of cross-breastfeeding in order to intervene, considering that most of the time it is practiced for the non-effectiveness of their rights.

Keywords: Breastfeeding; Counselin; Nursing; Bioethics.

\section{SILENCIO DE LOS ENFERMEROS SOBRE LOS MOTIVOS DE LA NO RECOMENDACIÓN DE LAAMAMENTACIÓN CRUZADA}

Objetivo: identificar cuál es la conducta asistencial del enfermero frente a la lactancia cruzada. Metodo: estudio cualitativo, realizado con seis enfermeras actuantes de la Estrategia de salud de la familia por medio de un grupo focal en el Duque de Caxias. Resultados: apunta la carencia del asesoramiento en la conducta asistencial frente a la lactancia cruzada y el silenciamiento sobre los motivos de la no recomendación de la misma. Conclusión: Se recomienda cambiar en los discursos de los enfermeros para la búsqueda de los motivos que desencadenaron la práctica de la lactancia cruzada para asi poder intervenir, ya que la mayoría de las veces es practicada por la no efectividad de sus derechos. Descriptores: Lactancia Materna; Consejo; Enfermería; Bioética. \footnotetext{
${ }^{2}$ Faculdade de Enfermagem da Universidade do Estado do Rio de Janeiro.

${ }^{3}$ Instituto de Saúde Coletiva da Universidade Federal Fluminense

Autor Correspondente: Cristiane Santos Gomes - Email: cris.s.gomes@hotmail.com
}

1Universidade Federal do Rio de Janeiro/Fundação Oswaldo Cruz/Universidade do Estado do Rio de Janeiro/Universidade Federal Fluminense.

Recebido: 04/03/2019 - Aceito: 21/11/2019 


\section{INTRODUÇÃO}

A amamentação cruzada é a prática de oferecer o leite materno a uma criança que não a sua própria. Trata-se de uma prática culturalmente aceita. As nutrizes que a realizam assim o fazem ainda na maternidade ou na comunidade com pessoas de suas escolhas justificadas por virtudes morais como a solidariedade, o bem e a confiança ${ }^{(1)}$, pois a decisão de amamentar está interligada à história de vida de cada mãe e ao significado que se atribui a esse ato (2).

Contudo, é uma prática não recomendada desde a década de 80 do século passado, por ser o leite humano um fluido biológico e que na vigência de uma doença, poderá ser uma fonte de infecção como outros fluidos secretados ${ }^{(3)}$.

Embora a amamentação cruzada seja contraindicada, na abordagem à nutriz o enfermeiro deve sempre promover um diálogo empático, buscando as razões que levam ou levaram a mulher a adotá-la. Existem alguns fatores indutores para prática da amamentação cruzada, como: mãe muito tempo longe de suas casas, trabalho ou estudo, baixa produção de leite ou ainda problemas na mama que impossibilitem o aleitamento materno. Tais condições condicionam as mulheres a ofertarem seu leite às crianças que não sejam seus filhos como uma alternativa solidária ${ }^{(1.4)}$.

O afastamento da criança e sua mãe não justifica a realização da amamentação cruzada, pelo contrário, para a Organização Mundial da Saúde o afastamento para o trabalho, por exemplo, sem que haja a possibilidade de manter/estocar leite materno, se constitui como uma das razões aceitáveis para a substituição pela fórmula láctea. Conciliar trabalho e amamentação tem sido relatado como causa para o desmame precoce ${ }^{(2)}$. Existe, para isso, a técnica de ordenha e formas de armazenamento do leite para ofertar a criança no período em que este se faz necessário.

Já nos casos de insuficiência lactacional percebida pela mulher, é importante lançar mão de estratégias de educação em saúde para desmistificar crenças de baixa produção como algo permanente sem possibilidade de reversão, para isso, é fundamental a intensificação das ações de incentivo e apoio ao aleitamento materno e no processo de capacitação dos profissionais de saúde que por vezes estão desatualizados ${ }^{(5)}$.

Em uma abordagem complexa como essa em que a amamentação cruzada envolve, por um lado, valores morais e de outro uma proibição devido ao risco de infecção, a utilização do aconselhamento, que é uma estratégia em que o profissional escuta ativamente a nutriz e com seus conhecimentos e habilidades oferece apoio na tomada de decisão consciente ${ }^{(6)}$ é de fundamental importância.

O aconselhamento tem seu embasamento teórico na construção de diversas habilidades, tais como a comunica- ção não verbal, empatia, ausência de julgamentos, desenvolvimento de confiança e na oferta de apoio, sendo recomendado como base para o manejo da amamentação( ${ }^{(7)}$.

Portanto, o objetivo deste estudo é identificar qual a conduta assistencial do enfermeiro frente à amamentação cruzada. O estudo justifica-se por contribuir para a ação do profissional de enfermagem em sua conduta assistencial a partir do conhecimento do problema. Considera-se relevante, pois a compreensão da conduta assistencial dos enfermeiros diante da amamentação cruzada possibilita (re) pensar quais ações podem ser tomadas para evitar sua ocorrência e prevenir danos à saúde da criança.

\section{METODOLOGIA}

\section{Tipo de estudo}

Estudo qualitativo do tipo descritivo com base metodológica de análise do discurso.

\section{Participantes da pesquisa}

Foram convidados a participar da pesquisa 22 enfermeiros que atuam na Estratégia Saúde da Família (ESF) dos quatro distritos do município de Duque de Caxias por meio da Coordenação da Atenção Básica na Secretaria de Saúde de Duque de Caxias. Desses, apenas seis aceitaram participar e foram codificadas por ENF 1 a 6, sendo duas do $1^{\circ}$ Distrito: uma do 2 ㅇ Distrito e três do $3^{\circ}$ Distrito. $\mathrm{O}$ critério de inclusão foi o acompanhamento de mulheres em amamentação ao trabalhar em USF e como critérios de exclusão: enfermeiros de licença no período da coleta de dados.

\section{Local de estudo}

Estratégia de Saúde da família do 1 ㅇ, 2 ㅇ e $3^{\circ}$ distritos do Município de Duque de Caxias.

\section{Coleta de dados}

A técnica de coleta de dados deu-se por meio de um grupo focal no mês de maio de 2016.

\section{Procedimentos de análise de dados}

Os dados de identificação dos participantes foram coletados com o preenchimento de um formulário pelos próprios, antes do início do grupo focal, para fornecimento de dados pessoais e questões sobre amamentação. $\mathrm{O}$ grupo focal iniciou com questões geradoras de debate de forma aberta, como: O que vocês entendem sobre amamentação cruzada?

Após esse momento, passou-se para segunda etapa do grupo focal, que foi uma discussão com recorte de falas de nutrizes que vivenciaram a amamentação cruzada e que participaram da pesquisa: Amamentação cruzada, da negligência 
às virtudes morais: estudo descritivo ${ }^{(1)}$. Nessa etapa, buscou-se identificar a conduta assistencial das enfermeiras frente à amamentação cruzada. O grupo focal teve duração de lhora e meia e foi gravado em vídeo.

Utilizou-se para análise de dados a análise do discurso, a qual interroga os materiais verbais e não verbais, a partir dos implícitos e dos jogos de sentido. Permite ir além do texto, trazendo os sentidos ocultos ${ }^{(8)}$.

Para a realização da análise do material produzido por essa pesquisa, foram transcritas as falas do grupo focal e construídos quadros analíticos para extrair os objetos discursivos através da formação discursiva dos sujeitos, em seguida se buscou os sentidos dos discursos e por fim, destacaram-se as marcas do referencial teórico no discurso dos sujeitos onde foram classificados e agregados em temas geradores, possibilitando o agrupamento por informações similares.

\section{Procedimentos éticos}

A presente pesquisa foi aprovada pelo CAEE $n^{\circ}$ 52512115.4.0000.5282 de fevereiro de 2016, e seguiu as orientações da Resolução no 466/2012 do Conselho Nacional de Saúde (CNS), que regulamenta a pesquisa em seres humanos no país.

\section{RESULTADOS}

Este estudo evidenciou que diante da prática da amamentação cruzada os enfermeiros se utilizam de censura e medo ao invés de uma escuta que valoriza a fala e a problematize, silenciando os motivos desencadeantes da amamentação cruzada.

Os resultados apontaram que de forma velada os enfermeiros apenas proíbem, sem investigar os motivos que levam à amamentação cruzada. O centro dos discursos recolhidos pelo grupo focal (técnica utilizada na coleta de dados) foi a proibição, e ela pode ser atestada pelo uso recorrente de modalizadores deônticos (relacionados à linguagem das normas) e não são buscados os motivos que desencadearam a prática.

Portanto, os principais temas representativos sobre a conduta assistencial do enfermeiro frente à amamentação cruzada são: carência do aconselhamento na conduta assistencial do enfermeiro frente à amamentação cruzada e silenciamento dos enfermeiros sobre os motivos da não recomendação da amamentação cruzada.

\section{Carência do aconselhamento na conduta assistencial do} enfermeiro frente à amamentação cruzada.

Os discursos a seguir denotam o método proibitivo/prescritivo nas consultas de enfermagem. $\bigcirc$ dizer não pode anu- laria a possibilidade da investigação das causas da amamentação cruzada.

O Ministério da Saúde proíbe né a amamentação cruzada que eu entendo que é você dar o seu neném para que uma outra pessoa amamente ele (ENF 5).

Esta fala mostra que a participante da pesquisa busca no campo científico (argumentos de autoridade) elementos que deixam transparecer credibilidade e cuidado nas suas ações de proibição. Ela tem a preocupação e cuidado em apresentar valor de verdade àquilo que afirma através de argumentos de autoridade (Ministério da Saúde). Assim, é uma tentativa de se isentar das prescrições, uma vez que essa voz na hierarquia de autoridade está acima do profissional de saúde.

Existem alguns marcadores de pressuposição, ou seja, de algo que está implícito, subentendido. São elementos linguísticos que permitem o entendimento de informações secundárias, não explícitas nos enunciados ${ }^{(9)}$. As falas a seguir apresentam várias marcas linguísticas que evidenciam a carência do aconselhamento na conduta das enfermeiras:

Hoje na comunidade a gente vistoria isso sim por mais que a gente fale, converso muito com as gestantes $E$ ai quando eu vou fazer a visita do puerpério eu chego lá eu converso, eu dou todas as informações de tudo que pode acontecer o que a gente pode eu até falo que a criança que vai ter algum problema contaminar que é justamente pra até por medo mesmo para que não venha fazer isso (ENF3).

Também a gente fala, orienta, mas eu procuro não recriminar, não brigar eu digo que não pode que é proibido pela lei explico, ai explico as coisas que podem acontecer com bebê (ENF 5).

Porque é muito comum lá eles mandarem chamar Fulana que é mãe de 10 filhos, 12 filhos que praticamente tem leite a vida dela inteira porque um filho atrás do outro e essa mulher que chega pra amamentar a criança, ai a gente tem que ter todo cuidado pra lidar pra falar que hoje em dia por causa das doenças (ENF 2).

Ao afirmar que fornece todas as informações, não há abertura para diálogo. O termo vistoria transmite uma ideia de verticalização de poder - um verbo transitivo direto com significado de inspeção, revista, supervisão. Esse autoritarismo que o termo remete deixa clara a ausência de diálogo problematizador, autônomo, no processo educativo. 
Além disso, a ameaça para produzir medo para que a lactante não pratique a amamentação cruzada não é eficaz, pois sem reflexão-ação ela não compreende a informação por completo e não alcança sua interdependência e autonomia para o processo decisório.

\section{Silenciamento dos enfermeiros sobre os motivos da não recomendação da amamentação cruzada}

O silenciamento pode ser identificado pela postura da profissional perante a lactante. Utiliza-se de um discurso verticalizado sem busca das causas que desencadearam a prática.

A gente passa informação, mas o que eu percebo, eu digo que eu não tenho ciência, mas logo, logo quando vai pra consulta com 2 meses já está com mamadeira. (ENF 1)

Eu nunca perguntei eu nunca fiz essa pergunta se o bebê já mamou em outra mãe em outra mulher eu nunca fiz essa pergunta. (ENF 2)

Agora uma coisa interessante é perguntar se outra mãe está amamentando porque isso eu não pergunto. (ENF 6)

Ai como o profissional fica? Porque tudo que ela fez, falou, orientou ficou pela metade. Porque até ali ela foi profissional, falou que não. (ENF 4)

O pensamento dos profissionais se dá por meio da transmissão de conhecimento, um modelo verticalizado, no qual os discursos pretendem manter o sujeito em um "caminho do não pode e ponto final", e está intimamente ligado ao poder. Devemos alterar esse paradigma através da construção de saberes mútuos entre educador e educando, alicerçados no diálogo, para contribuir com a formação de pessoas participantes.

Há necessidade da inserção da cultura e participação popular no processo de educação em saúde. É necessário que o profissional de saúde tenha sensibilidade e saiba lidar com cada pessoa individualmente para não ter empecilhos para o processo educativo em saúde.

\section{DISCUSSÃo}

A conduta assistencial baseada no aconselhamento é fundamental, pois o enfermeiro age como um elo entre o conteúdo teórico-científico e a prática que vai ser vivenciada pela mã $\mathrm{e}^{(10)}$. O encorajamento é preciso, além das condições necessárias para que as mulheres possam amamentar a qual- quer hora e em qualquer lugar. É fundamental o aconselhamento em toda rede de apoio, pois o indivíduo não vive isolado, mas inserido em um contexto histórico, social e cultural.

Em se tratando de amamentação cruzada, deve-se ter na discussão a liberdade e autonomia da mulher no seu processo decisório, contudo, há também de considerar o direito da criança à vida isenta de riscos, logo, só deve ser amamentado quando isso não implicar em nenhum prejuizo ou dano como transmissão vertical de doenças ${ }^{(11)}$. A aplicação da educação problematizadora expõe a capacidade de análise crítica de cada um sobre sua realidade, reflexão sobre ela e conscientização sobre seu papel social. Os educadores não são sabedores de tudo, logo, devem dar abertura para os saberes dos educandos, e como seres biopsicossociais, de lembranças históricas e culturais são capazes de construir sua história participando ativamente do processo de aprendizagem ${ }^{(12)}$

Identificou-se em um estudo que cuidados com as mamas, aleitamento materno e ações educativas estão entre as ações pouco frequentes no pré-natal realizado por enfermei$\operatorname{ros}^{(13)}$. A educação é um processo de troca, no qual, através do diálogo, as partes procuram se conhecer. Sem a comunicação não há a verdadeira educação, pois ela se constrói com o outro. Esse diálogo deve ser embasado com confiança. O conteúdo abordado deve ser compartilhado, não imposto ou depositado, pois dessa forma se constituiria em opressão. $\bigcirc$ profissional de saúde deve manter uma postura vigilante contra todas as práticas de desumanização(14).

Pelo aconselhamento partimos das dúvidas e necessidades da nutriz, então com perguntas abertas e sem julgamentos conseguimos identificar as causas que levaram a prática da amamentação cruzada e a partir disso intervir de modo que a conduza a reflexão de sua ação e faça uma escolha consciente para alimentar seu filho.

Portanto, os profissionais de saúde devem dar voz às nutrizes para que se torne possivel a compreensão acerca dos motivos da prática da amamentação cruzada. A partir desse conhecimento, os profissionais de saúde devem propor uma ação educativa que permita esclarecimentos sobre o porquê da não recomendação dessa prática para, com isso, alcançar o desenvolvimento da consciência crítica dessas mulheres, levando-as a transitar da tomada de consciência acrítica à tomada de decisão reflexiva.

A amamentação ao longo dos anos foi se tornando uma prática medicalizadora, impregnada de regras (frequência de 3/3 horas, alternância das mamas a cada 15 minutos de mamada; restrição alimentar da nutriz) enfraquecendo a confiança da mulher em sua própria capacidade de produzir o leite em quantidade adequada e nutrir o próprio filho(15). 
Da mesma forma, foi preciso modificar as práticas educativas bancárias que privilegiavam a transmissão do conhecimento e consideravam as nutrizes como página em branco para dar lugar a um processo educativo problematizador, dialógico, em que há uma fusão de conhecimentos ${ }^{(12)}$.

Isso converge em um processo de educação em saúde que só é possível em uma relação dialógica, na qual o enfermeiro que promove, protege e apoia a mulher e a criança que praticam a ação e estas se fundem para o alcance de um bem, de algo que com razão valoram, que não é viável sem considerar o outro agente de sua própria história(14,16)

O discurso em defesa da amamentação foi, ao longo do tempo, estabelecendo-se como um discurso autoritário por parte dos profissionais de saúde, com foco no dizer/impor ao invés de ação/conduta. Ainda em relação ao discurso, o dizer "não pode" e a ideia de desimplicação em seus relatos distancia a conduta aconselhadora de fortalecimento da autonomia das lactantes ${ }^{(15)}$

A conduta assistencial autoritária, com negação da autonomia, parece se dar de forma imperceptível, proporcionada por uma organização de trabalho com normas e rotinas institucionalizadas, nas quais as pessoas reproduzem em sua assistência quando têm um número grande de atendimento para um curto tempo para alcançar uma meta pré-estabelecida pela instituição(17)

A atuação dos enfermeiros para agir nos conflitos da amamentação requer atualização e reflexão no campo da bioética para intervir com competência técnica e respeito à autonomia da mulher e sua rede de apoio. Os enfermeiros têm como matéria-prima de seu processo de trabalho o próprio ser humano e concomitante toda sua peculiaridade, logo, através da técnica de aconselhamento será capaz intervir nas necessidades do outro com planejamento conjunto e respostas reciprocas ${ }^{(18)}$.

A discussão bioética possibilita despertar nas pessoas o senso do diálogo, visto que os valores, as atitudes e os julgamentos são o alicerce de sua reflexão, sempre aliando razão e emoção para garantir que as decisões dos conflitos morais possam efetivamente redundar em justiça.

As respostas predeterminadas não compõem a proposta da bioética. A complexidade do dilema e a reflexão pautada na bioética norteiam uma decisão mais adequada, sendo a reflexão uma estratégia para a condução das situações conflitantes.

\section{Limitação do estudo}

Este estudo possui limitações por ser uma pesquisa feita apenas em um municipio, necessitando de outros estudos semelhantes em outras regiões no âmbito nacional.

\section{Contribuições para a prática}

Este artigo traz como contribuição oportunidade de uma reflexão crítica sobre a amamentação cruzada. Propõe uma metodologia de um processo educativo dialógico com embasamento bioético pautado na horizontalidade e aconselhamento para promover a aproximação profissional-família pela escuta, reflexão e ação, a fim de empoderá-las para a escolha da alimentação de seu filho.

\section{CONCLUSÃO}

O foco dos discursos das enfermeiras é a proibição, não sendo buscados os motivos que desencadearam a prática da amamentação cruzada. Esse deveria ser o ponto de partida dos discursos dos locutores, já que é sabendo os motivos da prática que se pode intervir com orientações/aconselhamentos para a não prática.

Entretanto, seria prudente na vigência da amamentação cruzada convidar todos os envolvidos para grupos de discussão para, além de identificar os motivos da prática, também realizar exames periódicos de doenças transmissiveis pelo leite humano. Os grupos de discussão possibilitarão a tomada de consciência crítica, pois os participantes criarão e recriarão suas ações, explorarão a causalidade dos fenômenos, assimilando criticamente a realidade e tendo consciência de suas ações, possibilitando assim a construção da autonomia.

A persistência da amamentação cruzada traduz um efeito de ações não realizadas: capacitações profissionais e acadêmicas, efetivação de políticas públicas de proteção social; e o que sobressai nesse estudo é a conduta assistencial do enfermeiro de forma prescritiva sem investigação das causas de tal prática. Os enfermeiros são resultados de um processo de formação que ainda em muitos lugares não privilegia o outro, o que nos mostra que a mudança deve ser em todas as áreas, desde o processo de formação até a implementação e efetivação de políticas públicas.

Em todos os discursos dos profissionais apenas se demonstra a preocupação com o fazer valer a norma (não pode) e não se indagam as causas. Nesse caso, o dito e o não dito entrecruzados nos interdiscursos demonstram uma ausência de diálogo desejado numa relação entre pacientes e enfermeiros.

Portanto, os enfermeiros necessitam repensar sua conduta, estabelecendo um diálogo alicerçado em uma postura ética que não reproduza a norma, mas privilegie conhecimentos e atitudes que permitam à mulher realizar escolhas apropriadas ao seu modo de viver. Recomenda-se mudança nos discursos dos enfermeiros para a busca dos motivos que desencadearam a prática da amamentação cruzada para assim poderem intervir, visto que na maioria 
das vezes é praticada pela não efetividade de seus direitos.

Recomenda-se ainda mudança nas estruturas curriculares das instituições de ensino para inserção e aprofundamento desse tema tão relevante para saúde materno-infantil e sociedade em geral. Como enfermeiros, tendo como objeto do processo de trabalho o ser humano e suas singularidades, é de fundamental relevância trazer a bioéti- ca em todas as discussões de ensino. Além disso, espera-se que outros estudos emerjam a partir deste.

CONTRIBUIÇÃO DOS AUTORES: Concepção, desenho, análise, interpretação dos dados, redação do artigo: Cristiane Santos Gomes, Benedita Maria Rêgo Deusdará Rodrigues, Patricia Lima Pereira Peres. Revisão crítica e revisão final: Lilian Koifman.

\section{REFERÊNCIAS}

Gomes CS, Fonseca JSA, Peres PLP, Rodrigues BMRD. Cross-breastfeeding, from negligence to moral virtues: a descriptive study. Online Brazilian Journal of Nursing. [internet]. 2015 [cited 2018 Dec 5]: 14(3): 263-272. Available from: http://www.objnursing.uff.br/index.php/ nursing/article/view/5157

Diogo EF, Souza T, Zocche DA. Causas do desmame precoce e suas interfaces com a condição socioeconômica e escolaridade. Enferm Foco. [internet].2011 [cited 2019 Nov 6]; 2 (1):10-13. Available from: http://revista.cofen.gov.br/index.php/enfermagem/article/view/66/53

Silva O, Tavares LHL, Paz LC. As atuações do enfermeiro relacionadas ao teste rápido anti-HIV diagnóstico: uma reflexão de interesse da enfermagem e da saúde pública. Enferm Foco [internet].2011 [cited 2019 Nov 6]; 2: 58-62. Available from: http://revista.cofen.gov.br/index. php/enfermagem/article/view/83/69

Seehausen MP, Oliveira MIC, Boccolini CS, Leal MC. Fatores associados ao aleitamento cruzado em duas cidades do Sudeste do Brasil. Cad. Saúde Pública [Internet]. 2017 [cited 2019 Jan 02]; 33(4): e00038516. Available from: http://dx.doi.org/10.1590/0102-311×00038516

Lima MML, Silva TKR, Tsupal PA, Melhem ARF, Brecailo MK, Santos EF. A influência de crenças e tabus alimentares na amamentação. O Mundo da Saúde [Internet].2016 [cited 2019 Nov 7]; 40(2):221-229. Available from: https://pesquisa.bvsalud.org/bvsms/resource/pt/mis-37814

Vilchez Barboza V, Klijn T, Salazar Molina A, Sáez Carrillo K. Eficácia de uma intervenção personalizada de aconselhamento em enfermagem, presencial e telefônica, para fatores de risco cardiovascular: ensaio clinico controlado. Rev. Lat.-Am. Enfermagem. [Internet].2016 [cited 2019 Nov 7]:24:e2747. Available from: https://www.revistas.usp.br/rlae/article/view/124547

Barreto MAM, Ribeiro CMS, Paulino AF, Araújo GGN, Araújo MY, Lima ST. Aconselhamento psicológico e a atuação do psicólogo na unidade básica de saúde-UBS. Cadernos de graduação. Ciências Biológicas e da Saúde. [Internet]. 2016 [cited 2019 Nov 6] 3 (3): 227-244. Available from: https://periodicos.set.edu.br/index.php/fitsbiosaude/article/view/3685/2024

Gonçalves ATP. Análise de conteúdo, análise do discurso e análise de conversação: estudo preliminar sobre diferenças conceituais e teóricometodológicas. Administração: ensino e pesquisa [Internet]. 2016 [cited 2019 Nov 6] 17 (2): 275-300. Available from: https://raep.emnuvens. com.br/raep/article/view/323

Machado JC. 50 anos da pressuposição na semântica argumentativa. Cad. Est. Ling. [Internet]. 2019 [cited 2019 Nov 7]; 61:1-21. Available from. https://periodicos.sbu.unicamp.br/ojs/index.php/cel/article/view/8652865

Mendonça AB, Pereira ER, Barreto BMF, Silva RMCRA. Aconselhamento e assistência espiritual a pacientes em quimioterapia: uma reflexão à luz da Teoria de Jean Watson. Esc. Anna Nery. [Internet].2018 [cited 2019 Nov 7]; 22 (4): e20180081. Available from http://www.scielo.br/ scielo.php?script=sci_arttextEpid=S1414-81452018000400601\&lng=en\&nrm=iso

Roque-sanchez MV, Macpherson I. Análise da ética de principios, 40 anos depois. Rev. Bioét. [Internet]. 2018 [cited 2019 Nov 7]; 26 (2):189-197. Available from http://dx.doi.org/10.1590/1983-80422018262239

Maders S, Barcelos V. Pedagogia do oprimido - um legado generoso e esperançoso. Revista e-Curriculum, [Internet].2019 [cited 2019 Nov 7]:17 (1):168-183. Available from: http://revistas.pucsp.br/curriculum/article/view/39549/28067

Duarte SJH, Mamede MV. Estudo das competências essenciais na atenção pré-natal: ações da equipe de enfermagem em Cuiabá, MT. Enferm Foco, [Internet].2012 [cited 2019 Nov 7]: 3 (2): 75-80. Available from: http://revista.cofen.gov.br/index.php/enfermagem/article/view/259/147

Mendonça AMC; Rodrigues MEN, Souza NBAC. Uma reflexão sobre o livro pedagogia da autonomia, saberes necessários á prática educativa de Paulo Freire. Revista PLUS FRJ: Revista Multidisciplinar em Educação e Saúde [Internet].2019 [cited 2019 nov 7]; 6: 89-97. Available from: https://www.faculdadeplus.edu.br/wp-content/uploads/2019/04/ARTIGO-08-UMA-REFLEX\%C3\%830-SOBRE-O-LIVRO-PEDAGOGIA-DAAUTONOMIA.pdf

Alvarenga SC, Castro DS, Leite FMC, Brandão MAG, Zandonade E, Primo CC. Fatores que influenciam o desmame precoce. Aquichan [Internet]. 2017 [cited 2019 nov 7]:17(1): 93-103. Available from: http://dx.doi.org/10.5294/aqui.2017.17.1.9

Benjumea MVR, Falla NCM, Jurado LV. Conocimientos y prácticas de gestantes y cuidadores sobre lactancia materna en cinco municipios caldenses. Colombia. Hacia Promoc. Salud [Internet]. 2013 [cited 2019 Jan 03]; 18(2): 66-78. Available from: http://www.scielo.org.co/scielo. php?script=sci_arttextEpid=S0121-75772013000200006\&lng=en.

White MI, Wagner SL, Schultz IZ, Murray E, Bradley SM, Hsu V, McGuire L, Schulz W. Non-modifiable worker and workplace risk factors contributing to workplace absence: A stakeholder-centred synthesis of systematic reviews. Work. [Internet]. 2015. [cited 2018 dez 03];52 (2) 353-373. Available from: https://www.ncbi.nlm.nih.gov/pubmed/26409377

Rodrigues B, Peres P, Pacheco S. Boas práticas de maternança na perspectiva bioética: uma contribuição para a enfermagem. Revista Enfermagem UERJ. [Internet].2015. [cited $2018 \mathrm{dez}$ 03] 23(4): 567-571Available from: https://www.e-publicacoes.uerj.br/index.php/ enfermagemuerj/article/view/18944 